\title{
FROM STEM TO STEAM IN ENGINEERING DESIGN
}

\author{
Chantal Rodier, Mohamed Galaleldin, Justine Boudreau and Hanan Anis \\ University of Ottawa \\ crodier@uottawa.ca,mgala028@uottawa.ca,jboud030@uottawa.ca and hanis@uottawa.ca
}

\begin{abstract}
Creativity, communication skills, interdisciplinary sensitivity, and cultural and civic responsibility are vital skills and perspectives to inculcate in contemporary engineering students. A number of studies have demonstrated the benefits of exposing engineering students to arts, as studying arts and humanities can open up their minds to creative ideas from great minds outside of science and engineering. In most cases, engineering students are exposed to the arts by taking a few non-technical courses as electives. Many students view these courses as less important and irrelevant to their field of studies. Integrating the arts into the technical engineering curriculum is challenging but critical to engineering design, particularly in early years, and represents a natural opportunity. This paper discusses the approach taken by the Faculty of Engineering at the University of Ottawa of exposing students to the arts through curricular and extracurricular design activities. These include offering design challenges, a first-year engineering design course and summer internships. This paper also discusses the challenges that arise in delivering such curriculum and the impact of such exposure on the engineering students involved.
\end{abstract}

Keywords: STEAM, STEM, Engineering Design, Teamwork, Engineering Education.

\section{INTRODUCTION}

The University of Ottawa has progressively and successfully exposed its engineering students to art in STEAM projects, first by presenting them with an art client and an art challenge, then by adding some art training to their education, followed by having engineers and artists work together as STEAM teams during a summer internship to deliver full-size public art installations. The success of these experiments led to the creation of an in-class STEAM pilot project combining a sculpture course and an engineering design course. This paper discusses the challenges encountered throughout the experience, the impacts observed and the discoveries made along the way.

\section{BACKGROUND}

Engineering education needs to adapt to the fast pace of technological and organizational changes, which call for "new skills and understanding, not just the fundamental skills associated with a discipline but also the understanding of how to link information across multiple disciplines" [1]. The authors of a report commissioned by the Royal Academy of Engineering in the U.K. interviewed the executives of 30 engineering companies and found that "firms are looking to recruit engineering graduates who combine technical expertise with practical ability and commercial reality, backed up by strong interpersonal skills" [2]. Given what industry needs from engineering graduates, "it would appear that these demands are unlikely to be satisfied by a traditional engineering curriculum and 'chalk and talk' pedagogy" [4].

Traditional engineering instruction, "is deductive, beginning with the presentation of basic principles in a lecture and proceeding to the repetition and application of the lecture content by students" [5]. On the other hand, "arts based pedagogies are more inductive. Topics are introduced by presenting specific observations, case studies or problems, and theories are taught or the students are helped to discover them only after the need to know them has been established" [1]. Inductive teaching methods include "inquiry learning, problem-based learning, project-based learning and discovery learning" [1].

Studio-based learning [6] is common in the creative arts. It is based on a cycle of proposing, critiquing and refining ideas and artifacts. The emphasis is on learning by doing and recognizing that people must actively participate in doing things in order to assimilate and accommodate information, something that has long been acknowledged by psychologists [7]. Such approaches 
emphasize the use of formative assessment and are often based on promoting critical reflection and learner autonomy. These approaches place "the student at the heart of the learning experience and support the student in terms of defining their own learning journey, which becomes a vehicle for introducing disciplinary knowledge" [1]. Many researchers agree that studentcentric, inquiry-based teaching models may offer better alternatives to traditional models [1].

The need to use aspects of the delivery of arts programming in the teaching of the subjects of science, technology, engineering and mathematics (STEM) has been identified by many researchers [8], [9], [10], [1]. Connor, Karmokar and Whittington argue that "creativity and innovation cannot be treated separately from STEM, and 'arts' should be an integrating part of the puzzle that combines creativity and innovation into a unified whole" [1].

Lateral and vertical thinking, integrative analysis, innovation and synthesis, and contextual understanding capabilities are part of the puzzle of developing creativity and innovation in engineering education [12]. Engineering education could therefore benefit from a shift in the traditional focus of teaching the STEM subjects by "unifying the functional core of an engineering process with the liberal arts, and developing an integrated learning process that is followed throughout the delivery of engineering programmes" [1].

Georgette Yakman, an early proponent of integrating art into STEM education to create STEAM, credits the work of Swiss psychologist Jean Piaget with providing insight into how knowledge develops in humans and helping to inform the thinking behind integrating art into STEM education. "His primary tenant was that knowledge was a constant development of misconstrued connections that were adjustable usually through developing deeper understanding. It was promoted that a reality-based (contextual) learning style was the most conducive learning environment" [13]. Yakman's review of education models leads her to conclude that students need to develop knowledge in a range of disciplines in order to be functionally literate [13].

Watson and Watson argue for recognizing the value of art and imagination in the process of generating scientific knowledge. They cite great thinkers such as Nobel laureate Jacobus Henricus van 't Hoff and Albert Einstein to make their case: Hoff said he believed true scientific imagination is correlated with and supported by creative activity outside science. Albert Einstein agreed with this viewpoint, "I am enough of an artist to draw freely upon my imagination. After a certain high level of technical skill is achieved, science and art tend to coalesce in esthetics, plasticity, and form. The greatest scientists are always artists as well." [14]

Encouraging a more holistic approach to engineering education becomes all the more important "as technology becomes an ever more dominant aspect of social issues" [15]. Connor, Karmokar and Whittington suggest that "an examination of liberal arts pedagogics may improve the uptake of student-centric learning in STEM subjects." [1] They argue for arts-based pedagogies to be integrated into STEM subjects as a way to promote inquiry-guided learning in STEM subjects.

Watson and Watson also present practical arguments for including art education in STEM, namely that the "inclusion of artistic thinking in the education of scientists and engineers improves their ability to create relevant products and services. The resulting paradigm shift disrupts the structured, logical flow of the thinking processes that are encouraged by the traditional STEM disciplines." [14]

In education, as well, the arts have already been shown to reinforce engineering learning, and vice versa. "In many arts classes, the STEM disciplines already are being taught as a means to attain professionalism in the use of media. For instance, the physics of light, basic chemistry, and fundamentals of trigonometry are key learning areas in photography. In teaching computer graphics or game design, it is necessary to provide a foundation in mathematical thinking, geometry, and software programming. The inclusion of the arts in teaching STEM, therefore, does not minimize any aspect of the STEM disciplines; it makes them stronger, more engaging, and relevant to students" [14].

Given the increasingly "non-linear design of complex systems" [8], such systems "need to be investigated and tested as wholes, which requires a cross-disciplinary approach and new conceptual principles and tools. Consequently, schools cannot continue to only teach isolated disciplines based on simple reductionism" [8]. Boy argues that "creativity and design thinking should be promoted at the same level as analysis and reasoning" [8]. Calls for the inclusion of art education go beyond engineering and the other STEM subjects, to include such subjects as business and management: "The purpose of inclusion is to enhance artful behaviour aesthetics and creative in managers and business organizations with implications for business innovation" [17]. 
Ultimately, incorporating art into engineering education enriches the education "by exposing students to a different way of seeing the world. Students learn through different pedagogical modalities engaging their other interests. By applying the STEM disciplines, combined with real-world experience, students become more comfortable in both worlds" [14].

\section{RESEARCH QUESTIONS}

RQ1: How does introducing art in STEM projects affect students in engineering and art? What kind of knowledge transfer takes place?

RQ2: What are the challenges facing the teaching team in delivering STEAM projects?

\section{STEM TO STEAM AT THE UNIVERSITY OF OTTAWA}

\subsection{Integrating Art in Engineering Design}

There are many ways to integrate art and engineering. Artists can bring artistic aesthetics to an engineering project, or engineers can bring engineering grounding to an artistic project. However, the goal of the University of Ottawa is to have artists and engineers work as equal collaborators to create projects neither could have created individually. We targeted our first-year design course and a summer internship program to introduce more art into engineering education.

\subsubsection{Engineering Design Courses at the University of Ottawa}

There are two cornerstone engineering design courses at the University, a first- and a second-year course, where students learn and apply design knowledge while working in teams. Each team is expected to develop three prototypes during the semester and solve a design problem for a client.

The engineering design course projects are mechatronic, civil or software in nature and can include mechanical, electronic, hardware and software parts.

\subsubsection{Progression from STEM to STEAM}

In their design courses, many engineers tend to take a purely functional approach to projects. However, given the growing need for engineering education to include more creativity, divergent thinking and multidisciplinarity, we have progressively introduced art and creativity training into the engineering design courses at the University of Ottawa.

Since 2017, a number of engineering design students have been exposed to artistically oriented projects that have allowed them to apply their theoretical knowledge to hands-on projects requiring both technological and creative skills. We are effectively exposing our students to STEAM projects by introducing art (A) to STEM design projects.

By introducing the engineering students to interdisciplinary STEAM initiatives, we aim to spark their imagination, develop their creativity, expose them to the benefits of arts and humanities, and help them innovate while applying creative thinking and design skills to hands-on projects. Moreover, they are exposed to a more diversified selection of design challenges, and they collaborate with fellow arts students whom they would not otherwise have the opportunity to work with. As a result, they witness and participate in artistic creative processes that influence their design approaches.

This exposure allows engineering and arts students to step outside their respective disciplines, understand other perspectives and expand their world view.

Beyond curriculum courses, engineering students are also invited to participate in the Makerspace Challenge, an annual design challenge hosted by the University of Ottawa's Richard L'Abbé Makerspace and open to all students to participate by submitting a prototype for prize and pride. The Makerspace Challenge has also embraced the STEAM approach.

The following subsections describe the progressive steps we took to go from STEM to STEAM at the University of Ottawa. These steps are summarized in Table 1.

Table 1. Progression from STEM to STEAM.

\begin{tabular}{|c|c|c|c|c|c|c|}
\hline Section & $\begin{array}{c}\text { Project } \\
\text { Name }\end{array}$ & Challenge & $\begin{array}{c}\text { Art } \\
\text { Project }\end{array}$ & $\begin{array}{c}\text { Art/ } \\
\text { Culture } \\
\text { Client } \\
\end{array}$ & Team & $\begin{array}{c}\text { Art } \\
\text { Train- } \\
\text { ing } \\
\end{array}$ \\
\hline 4.1.2.1. & $\begin{array}{c}\text { MKS } \\
\text { Challenge } \\
\text { Design } \\
\text { Course 1 } \\
\end{array}$ & $\begin{array}{l}\text { Steampunk } \\
\text { wearables }\end{array}$ & $\checkmark$ & $\checkmark$ & Eng. & \\
\hline 4.1.2.2. & $\begin{array}{c}\text { MKS } \\
\text { Challenge } \\
\text { Design } \\
\text { Course 2 } \\
\end{array}$ & $\begin{array}{l}\text { Interactive } \\
\text { art } \\
\text { installations }\end{array}$ & $\checkmark$ & $\checkmark$ & Eng. & $\checkmark$ \\
\hline 4.1.2.3. & $\begin{array}{l}\text { STEAM } \\
\text { Internship }\end{array}$ & $\begin{array}{l}\text { Interactive } \\
\text { art } \\
\text { installations }\end{array}$ & $\checkmark$ & $\checkmark$ & $\begin{array}{l}\text { Art/ } \\
\text { Eng. }\end{array}$ & $\checkmark$ \\
\hline 4.1.2.4. & $\begin{array}{c}\text { Design } \\
\text { Course } 3 \\
\text { Sections F1 } \\
\text { \& F3 }\end{array}$ & $\begin{array}{c}\text { Improving } \\
\text { interactive } \\
\text { art } \\
\text { installations }\end{array}$ & $\checkmark$ & & Eng. & \\
\hline 4.1.2.5. & $\begin{array}{c}\text { Design } \\
\text { Course } 3 \\
\text { Section F2 } \\
\text { \& Sculpture }\end{array}$ & $\begin{array}{l}\text { Recycled } \\
\text { kinetic } \\
\text { sculpture }\end{array}$ & $\checkmark$ & $\checkmark$ & $\begin{array}{l}\text { Art/ } \\
\text { Eng. }\end{array}$ & $\checkmark$ \\
\hline
\end{tabular}




\subsubsection{Steampunk Wearables}

The first attempt to integrate art into STEM projects at the University of Ottawa was inspired by the National Science and Innovation Gala, a Canada 150 celebration held in 2017 at the Canada Aviation and Space Museum. The theme of this gala was steampunk, as featured in exhibits and a fashion show. It became the theme of the University's third annual Makerspace Design Challenge and of a project for the first-year engineering design course in winter 2017 (Design Course 1). The student teams competed in the challenge for the chance to win $\$ 1,000$ and participate in the gala. Their challenge was to create an interactive wearable piece to be showcased during the gala, either in an exhibit or worn by a model.

As electrical and civil engineering students worked together in the course, they had an added challenge of designing their wearable technology to fit within the steampunk theme of the gala. This meant that the aesthetics of the project needed to fit the steampunk theme and be approved by the gala organizer, who was the client for the design course.

The students in the first-year course and the other participants in the Makerspace Challenge were able to deliver impressive prototypes and wearables that incorporated technology like heart rate sensors, neopixels and fog machines while fitting perfectly within the steampunk genre. Many of these projects were showcased at the gala along with their creators.

\subsubsection{Interactive Art Installations}

In 2018, the Faculty of Engineering and the Faculty of Arts co-launched the fourth edition of the Makerspace Challenge by welcoming students to build a prototype for a futuristic interactive art installation. Students were asked to create a prototype of an interactive art installation to present on Design Day, a Faculty of Engineering showcase event. One objective of the challenge was to create interdisciplinary teams of students from arts and engineering. However, cross-faculty teaming up did not occur naturally, as only engineers responded to the challenge.

Simultaneously, one of the sections of the first-year engineering design course (Design Course 2) was assigned the same challenge. During the winter semester, the engineering design course guided students through design thinking methodology, and a public art professional, chosen as the course client, helped students get basic art training on criteria and strategies for creating quality art installations. On Design Day, 16 projects were presented in the Makerspace Challenge category, and external judges declared a winning project. Many of the prototypes had the potential for full-scale implementation, despite needing important artistic input. Therefore, a collaboration between engineering and visual arts was established to bring two selected prototypes to full-scale implementation during summer a 2018 STEAM internship.

\subsubsection{STEAM Internship}

To pursue the interdisciplinary initiative and to pilot new ways of working across faculties, a STEAM summer internship was created in 2018. The internship objective was to take the two best prototypes created in the winter, select a multidisciplinary team composed of four artists and four engineers, and ask them to develop full-fledged installations during the summer. In collaboration with technicians and professors from both engineering and visual arts, students produced two professional-quality interactive art installations that were permanently installed as student public art in the new STEM building on campus. Students had access to both engineering fabrication facilities (the Richard L'Abbé Makerspace and the Brunsfield Centre machine shop) and visual arts facilities (the Atelier CoFab Lab and welding, woodworking and media rooms).

\subsubsection{Improving Interactive Art Installations}

In winter 2019, students in one of the first-year engineering design course (Design Course 3) subsections were challenged to improve the existing interactive art installations created during the STEAM internship, by modifying or adding to them. Engineering students who led the summer STEAM internship became the clients for this project. They identified potential improvement areas to guide students. The resulting prototypes were limited in interest and scope.

\subsubsection{Sculpture and Engineering Design Course}

After a successful summer STEAM internship, both the Faculty of Engineering and the Faculty of Art agreed to pilot a STEAM course combining engineering and arts students in a classroom setting. In this pilot, the studio portion of a sculpture course was combined with the lab section of an engineering design course. (Design Course 3 F2). Consequently, art students had a lecture portion on art theories, while engineering students had a lecture portion on design thinking processes, team and project 
management, and other engineering theories. Artists and engineers then came together in a weekly three-hour studio/lab session to produce a kinetic sculpture using recycled materials. The client was Recycl'ART, a local recycled art festival, that planned to exhibit and tour the students' creations during the summer of 2019.

\section{METHODOLOGY}

Participants for this study were engineering and arts students in the STEAM summer internship, as well as engineering students registered for an introduction to engineering design course and arts students registered for a sculpture course. Purposeful sampling was used to identify student teams that had engineering and art students working together. Participants were invited to participate in semi-structured interviews to discuss their experience in the course. Semi-structured interviews were selected as the data collection method because they are well suited for exploring complex and sensitive issues and they allow the researcher to ask follow-up questions to clarify the respondents' answers [19].

Interview questions were designed to capture students' perceptions about the course's learning environment, their team dynamics, and the multidisciplinary nature of the course. Interview questions were first tested on two of the student teams to ensure that the questions were focused and properly sequenced. To reduce any bias, the interviews were conducted by a researcher who is not a member of the instruction team. A total of 15 students from four teams were interviewed. Table 2 presents the characteristics of the student-teams considered for this study.

The data collection for this paper occurred during week 7 and week 10 of the winter and summer terms of the 2018-2019 academic year. Interviews were conducted towards the end of the semester, outside the studio/lab, and lasted for an average of 40 minutes. Interviews were then transcribed verbatim, and thematic analysis was used to identify patterns, themes and categories from the interview data. This paper presents a preliminary analysis of the interview data.

Table 2. STEAM team members interviewed.

\begin{tabular}{|l|c|c|c|c|}
\hline Teams Interviewed & Eng & Art & Male & Female \\
\hline Summer Internship - Surface Tension & 1 & 1 & 1 & 1 \\
\hline Design Course 3-Recycling - Team 6 & 2 & 2 & 3 & 1 \\
\hline
\end{tabular}

\begin{tabular}{|l|l|l|l|l|} 
Design Course 3-Recycling - Team 12 & 2 & 2 & 2 & 2 \\
\hline Design Course 3-Recycling - Team 14 & 2 & 3 & 2 & 3 \\
\hline
\end{tabular}

\section{RESULTS AND DISCUSSION}

Students in the internship and in the courses were interviewed and asked to share their experience based on open-ended questions to address our research focus. Artists and engineers were interviewed (together and individually). Interviews were reviewed, and answers were collected. The following sections outline their answers and our analysis. See Appendix A for additional quotes.

\subsection{Challenges Encountered}

The interviews revealed that communication was a challenge that all the multidisciplinary teams had to work on. Different disciplines use different knowledge bases, terminology, lexicons and references. This initially caused difficulties for team members in trying to understand each other.

"At the beginning, there were words that the artists were using that I just didn't understand - I had never heard before. Like, "motif" was one of them [laughs] - I don't even know how to spell it [laughs], forget about it. [laughs]." (Summer internship engineering student, male, surface tension team)

"Some of their terminology, in my mind, would mean something totally different, but to them is something very specific to engineering. So then I'm like, 'wait, you need to explain that.' And then, sometimes the same with us too, like, we talk about things and they're like, 'wait, what is that?' So then we'd take the time to explain to them.' (Design Course 3-Recycling art student, female, team 14)

Artists reported having to "educate" engineers about art movements and basic principles of art, and engineers shared having to explain forces, circuit design and other topics. Once a team recognized the need to develop a common knowledge base of terminology and key concepts, they adapted by educating each other, and their team dynamics greatly improved.

"We brought up, like, the concept of the Marcel Duchamp's ready-made pieces, and they were like, 'what does that mean?' And we're like, 'oh, like, an artist who took everyday objects, signed them and made them his pieces.' Like, we are using recycled items that were already made to create a new piece. So, there were ties to 
art history references that they were unaware of that now make sense." (Design Course 3-Recycling art student, female, team 14)

"The way that they see the world is different than the way I find that artists or the art group sees the world because there's a little bit of difference in mentality, which I thought was very interesting. How we spoke to them - you can use fancy words such as the feelings that the sculpture will give, the atmosphere, all that stuff... It's going to do this, it's going to do that. Just different languages." (Design Course 3-Recycling art student, female, team 12)

Good team integration is the objective we aim for with our teams, especially our multidisciplinary teams. However, it is difficult to achieve systematically. We can set the environment and offer supportive training to make conditions conducive to it (communication tools, personality type training, etc.), but effective integration happens only when students are willing to address and resolve important conflicts. We consider a team wellintegrated when an engineer gives us the thematic and artistic pursuit of their team's project or when an artist describes the considerations given to the moments of force applied to their structure and how they designed accordingly.

\subsection{Impacts for Students}

Students in both arts and engineering reported positively on learning from each other and understanding the perspective of the other discipline. Groups reported an increased understanding and openness towards new disciplines and towards multidisciplinary teams, something that help them learn from each other. In wellintegrated teams, all the team members adopted some elements of each other's discipline. This was manifested, for instance, in the way that artists expressed their theme and concept while mentioning the engineering considerations that affected their decision, and in the way that engineers would explain their projects while mentioning the artistic considerations.

"I learnt to communicate with individuals of different mindset than me and different capabilities as well. It was refreshing, I would say. I'm already a very open and patient person, but it really made me develop those skills of being a team player and understanding that others are either limited to certain things or others are not limited to certain things." (Design Course 3-Recycling engineering student, male, team 12)

"So, when the artist said to me: 'all the art you see, it looks nice but if you really look into it, all the stuff that look nice also says something really cool.' And the people that, you know, make these really cool things, that say something, 'this is, like, the important work that is kind of going on in the world and this is what we should be focusing on.' So, I think that was the big learning experience for me." (Summer internship engineering student, male, surface tension team)

"Our ways to approach projects typically would be more in technical terms - like, it has to meet these physical aspects, it has to weigh at most this much, and it has to be this size. In general, the three artists in our group will look at it more as being like it has to look more this way, not so much it has to be this size. I know that's changed my perspective a lot, because now in the back of my head, I'm always thinking 'Does it look the way we want?" (Design Course 3-Recycling engineering student, male, team 14)

Students also reported developing an appreciation for other skill sets and diversity, and they revealed the extent to which the projects were successful in breaking down stereotypes they had of each other.

"There's lots of value in having different strengths in this team. Having a diverse team can help a lot.... Yes, because we're two painters, and she's a photographer, and they are civil and electrical, so it's a little bit of everything I guess." (Design Course 3-Recycling art student, female, team 14)

"We were worried about them not wanting to work with us because we're art students." (Design Course 3Recycling art student, female, team 14)

"Well, yeah, I heard things about engineers being difficult to work with so that was definitely my biggest Don't give me that look! That was the biggest concern. I didn't know if I was gonna be able to communicate with them properly and get my ideas across. But that ended up not being the problem after all. Me and a lot of arts students were pretty taken aback at first. It was a problem at first, but it became really clear that it wasn't about the whole stereotype, just the whole language barrier. That was just it." (Design Course 3-Recycling art student, female, team 12)

Introducing STEAM projects to engineering and arts students challenges the traditional conception of engineering applications and related fields of work in a 
way that might contribute to increasing female enrolment (which was $22 \%$ in 2017 for undergraduate engineering programs in Canada [20]). As an example, during the STEAM summer internship, students worked in close contact with the building architects where their public art works were installed. As a result, an artist and an engineer have since decided to pursue architectural-related studies.

"This whole experience made me so much more confident. And I think, at least in my program, I got so many more opportunities. I am sort of the person that is giving the tours now, and I am making way more connections. I got a job working at the Makerspace, which is just like incredible - I am having so much fun. And think it is just helping me keep an open mind about everything I am going to be doing in the future. I am not planning on going on one path anymore - so, yah!" (Summer internship art student, female, surface tension team)

"After working on this project, I've gotten a lot of new opportunities, not just in technologies. But for example, one of the artists that came in to critique our work this summer, ah, I'm now working for her doing a lot of the engineering drawings for her. She does public art and she needs to make a foundation and she wants things to move, so I'm now being involved on that side of things. Ah, but even the way that I think about the work that I am going to be doing in the future, I want it to be influenced by art and design - have that sort of angle to it. I am not looking to do regimented, strictly engineering work anymore." (Summer internship engineering student, male, surface tension team)

\subsection{Discoveries}

Over the last few years, we have learned from our students and made some significant discoveries that have challenged our a priori assumptions.

\subsubsection{More Similar Than Different}

One of the assumptions was that art and engineering students would have to overcome significant differences to work together efficiently. However, the students reported that after addressing the initial communication challenges due to their lexicon and knowledge-base differences, they found themselves to be more similar than different. High-performing teams specifically expressed wanting to avoid stereotypes and labels and chose to share project tasks on a voluntary and interest basis, rather than based on their field of study.
"I still feel, like, for me, I can see the differences. But it's not like you guys are totally different. [The differences are], like, very minimal. ... Coming in, you think there's going to be a huge difference, and every so often you'll see little glimpses of the stereotypes if you will, but it's, like, subtle" (Design Course 3-Recycling engineering student, male, team 14)

\subsubsection{No Reluctance Detected}

Another a priori assumption from the art teaching team members was that engineering students would be reluctant to embark in an arts-oriented project. However, we did not experience any pushback. In fact, in some cases, it was the opposite: students expressed excitement. Our careful selection of art challenges was likely conducive to significant technological integration.

"Well, same thing, we weren't told we were going to be working with arts students either. The eng design course has been around for a while as far as I know, and then usually they'll work on, like, more construction-based projects or something and, same thing, first day we showed up and were told that we were going to be collaborating with arts students. At first, I didn't really know what to make of it because I didn't know what that would mean for us and, like, if we're still doing all the same stuff as the other groups or if it's going to be art projects. But same thing, I'm glad I stuck with it. ... In the end it turned out to be pretty fun, and we still learnt a lot." (Design Course 3-Recycling engineering student, female, team 14)

\subsubsection{Why vs How to: Significant Difference in Approach}

Finally, along with the discovery of their communication differences, students discovered that each discipline differs in its approach and general outlook. They empirically discovered that art students tend to question the fundamental reasons, the why of the project, while assessing actions and decision in relation to the overarching project thematic. On the other hand, engineering students were naturally concerned with the how to of the project. Once the team members' different perspectives were understood and integrated constructively, high-performing team members retained their fundamental natural perspectives (art students were still concerned with the why, and engineering students with the how to), but they each gained conscious considerations for the other perspectives. 
"So, initially when we were working on the prototype for the design show, we were not really thinking about what was the subject and what is the message that piece is trying to put across. So, after we won the competition, and we started to work on it in the summer, we were working with artists - they said, 'eh guys, we can make something that looks cool and that kind of feels cool, but if it does not say something and does not like give a message, then it is just something that looks cool.", (Summer internship engineering student, male, surface tension team)

"We definitely had different ways of thinking. I think when I go into something I look at - when I am making art, at least, I kind of work in an essay format. I figure out what the thesis is, the concept, then I start doing research to make that happen. Whereas, I think the engineers, they start off with maybe the idea and prototype it, and keep prototyping it and working on it. And they are not fixated on what this overall idea might be, they just kind of let it happen. And I think that this project worked so well because we sort of met halfway and used both methodologies." (Summer internship art student, female, surface tension team)

\subsection{Teaching Challenges, Impacts and Discoveries}

\subsubsection{Teaching Challenges}

The added challenges posed by a multidisciplinary teaching team were something we underestimated in this implementation of the STEAM experience. Our teaching team was composed of six individuals: one engineering professor, two art professors, and three teaching assistants. We realized the importance of building good team cohesion and of regular synchronization within the teaching team. Just like our multidisciplinary student teams, our multidisciplinary teaching team also required a certain level of communication training, conflict management and team integration, because teaching different disciplines requires different teaching vocabulary, practices and methodologies. Moreover, many of the teaching team members were new to their role, which brought additional challenges that we could have avoided with seasoned individuals. Synchronizing all the moving parts (i.e., six teaching team members) was a challenge at the beginning of the semester.

There also needs to be proper training for teaching assistants to able to provide a scaffolding role for both engineering and arts students. Labs should be designed to account for the differences in backgrounds and expertise level.

\subsubsection{Teaching Impacts}

The way we addressed the students as artists and engineers showed our biases, and this was not welcomed by students in general. As we discovered in the interviews, students preferred to move beyond stereotypes and instead to focus on each team member's interests.

"Well, it was like in class, they were called 'the engineers' and we were called 'the artists.' The artists got to choose the engineers and then we kinda went into the team with that mentality. ... Yeah: you do the engineering, we do the art." (Design Course 3-Recycling art student, female, team 12)

\subsubsection{Teaching Discoveries}

Arts students and engineering students pointed out that the design thinking approach used in the engineering design course was more rigid than the approach in the regular creative studio process. We have to investigate this discovery further to decide how to adapt in our next STEAM implementation.

"We, on the other hand, were doing things that the art students deemed were out of order or not the way art projects are usually approached. This clash of functionality and structure against artistic creativity and freedom is what I shall remember from this project, for it is quite an interesting contrast and highlights the differences in how engineers and artists design things. Engineers plan everything out and do analyses before even constructing anything, while artists have a more divergent process of design and don't plan every step of the way. Instead, they adapt as they move forward with their design.” (Design Course 3-Recycling engineering student, female, team 6)

\section{CONCLUSION}

STEAM design projects involving students from different faculties can be challenging to organize and manage for successful outcomes. There are many factors to consider, and a lot of effort must be made to maximize the chance of a positive experience all around. However, artistic clients and students in engineering and arts all realize the benefits of working together. All parties learn and expand their world view from the experience. 
Students acquire invaluable multidisciplinary team experience, interdisciplinary openness and knowledge while working on hands-on creative projects with a reallife client. Key to the success of the STEAM adventure is good communication and coordination at all times within the student teams, between students and the teaching team and within the teaching team itself. Among other skills, our students learn that conflicts are frequent but can have positive outcomes. They are trained on how to resolve them, which is key to teamwork in general but particularly crucial in multidisciplinary teams where each member joins with different references, lexicons and work practices.

In the future, the University of Ottawa would like to expand the STEAM course offering to a full-fledged common curriculum. Moreover, we would like to work with clients in other art disciplines to expand the STEAM subjects covered and to integrate artists with other practices.

Creativity is an attribute that can be cultivated and developed [12]. In future research, we would like to observe the impact our STEAM projects have in developing the creativity of our engineering students by using creativity tests and other methods.

We also want to correlate the observations made in this paper with differences in personality between the team members (or groups), as well as differences in personality over the semester, using OCEAN (openness, conscientiousness, extraversion, agreeableness and neuroticism) personality trait tests and peer evaluations for 2017-2018.

Furthermore, we are interested in further exploring multidisciplinary team dynamics, communication and information transfer.

\section{Acknowledgements}

Without our arts clients, none of our STEAM success would be possible. We thank them infinitely for the time they spend with us. We would also like to thank the Chair of the Department of Visual Arts for her willingness to embark on this adventure. These programs are possible due to the NSERC Chair in Entrepreneurial Engineering Design.

\section{References}

[1] A. M. Connor, S. Karmokar and C. Whittington, "From STEM to STEAM: Strategies for Enhancing Engineering \&
Technology Education," International Journal of Engineering Pedagogies, vol. 5, no. 2, pp. 37-47, 2015.

[2] N. Spinks, N. Silburn and D. Birchall, "Educating Engineers for the 21st Century: The Industry View," Henley Management College, March 8, 2006.

[3] P. A. Johnson, "Problem-based, cooperative learning in the engineering classroom," Journal of Professional Issues in Engineering Education and Practice, vol. 125, no. 1, pp. 811, 1999.

[4] J. Mills and D. Treagust, "Engineering Education - Is Problem-Based or Project-Based Learning the Answer?" Australasian Journal of Engineering Education, 2003.

[5] M. J. Prince and R. M. Felder, "Inductive Teaching and Learning Methods: Definitions, Comparisons, and Research Bases," Journal of Engineering Education, vol. 95, pp. 123-138, 2006.

[6] J. Lackney, "A history of the studio-based learning model," $1999 . \quad$ [Online]. Available: http://www.edi.msstate.edu/work/pdf/history_studio_based _learning.pdf.

[7] J. Piaget, The construction of reality in the child. London: Routledge, 1954.

[8] G. A. Boy, "From STEM to STEAM: Toward a HumanCentered Education, Creativity \& Learning Thinking," presented at the European Conference on Cognitive Ergonomics (ECCE 2013), Université Toulouse le Mirail, France, 2013.

[9] G. Boy, "What Space can contribute to Global Science, Technology, Engineering, and Mathematics (STEM) Education," presented at the 63rd International Astronautical Congress, Naples, Italy, 2012.

[10] M. E. Madden, M. Baxter, H. Beauchamp, K. Bouchard, D. Habermas, M. Huff, B. Ladd, J. Pearon and G. Plague, "Rethinking STEM Education: An Interdisciplinary STEAM Curriculum," Procedia Computer Science, vol. 20, 541-546, 2013.

[11] N. Herrmann, "The Creative Brain*," Journal of Creative Behavior, vol. 25, no. 4, pp. 275-295, 1991.

[12] J. Bordogna, E. Fromm, and E. W. Ernst, "Engineering Education: Innovation Through Integration," Journal of Engineering Education, vol. 82, pp. 3-8, 1993.

[13] G. Yakman, "STEAM Education: An Overview of Creating a Model of Integrative Education," Virginia Polytechnic and State University, 2008.

[14] A. D. Watson and G. H. Watson, "Transitioning STEM to STEAM: Reformation of Engineering Education," Journal for Quality and Participation, 2013.

[15] J. J. Duderstadt, "Engineering for a Changing World," in Holistic Engineering Education, D. Grasso and M. Burkins, Eds. New York: Springer, 2010, pp. 17-35.

[16] A. Wright, The Imagineering Field Guide to Magic Kingdom at Walt Disney World. New York: Disney Editions, 2005. 
[17] C. Kerr and C. Lloyd, "Pedagogical learnings for management education: Developing creativity and innovation," Journal of Management \& Organization, vol 14, no. 5, pp. 486-503, November 2008.

[18] M. Galaleldin, J. Boudreau and Hanan Anis "Integrating Makerspaces in Engineering Design," University of Ottawa, 2019. Manuscript submitted for publication.

[19] K. L. Barriball and A. While, A. "Collecting data using a semi-structured interview: a discussion paper," Journal of Advanced Nursing, vol. 19, no. 2, pp. 328-335, 1994.

[20] Engineers Canada, "Enrolment and Degrees Awarded Report: Canadian Engineers for Tomorrow - Trends in Engineering Enrolment and Degrees Awarded 20132017," 2017.

\section{APPENDIX A}

Communication challenges:

"Sometimes, we just kind of have to say, like, 'What? What did you say? What does that mean?' But no one's afraid to say, like, 'Please start back here' [general laugh]." (Design Course 3-Recycling art student, female, team 14)

"Just talking about abstract and abstract shape was challenging. Yesss, oh my god. At the very beginning, I was like, 'we're gonna make a concrete thing like a fish or a butterfly,' and they were talking about abstract and then we'll figure out the meaning after." (Design Course 3-Recycling engineering student, male, team 12)

"I feel like I didn't actually understand what art was until I really communicated with them." (Design Course 3-Recycling engineering student, male, team 12)

"Before this, I actually don't know if I've ever said 'aesthetics' before. So, like, terminology like that and their perspective of seeing things is something I picked up on." (Design Course 3-Recycling engineering student, male, team 14)

\section{Conflict management:}

Conflict management is an important aspect of the engineering design course curriculum. Students learn about different types of conflicts, their natural attitude towards conflicts and effective conflict resolution approaches. This training facilitates all our design teamwork but was even more crucial to the success of multidisciplinary teams. Teams that experienced and resolved conflicts in a constructive manner became more integrated and produced more successful projects.

"The other artist working on the project and I-we come from different backgrounds. We work with different mediums, and we have different interests. She is in sculpture, and I am in photo. So, we had to come to an agreement as well, which was also very difficult. I am so used to working on my own, and I have the concept, I have the idea, and I had to give some room for other people." (Summer internship art student, female, surface tension team)

"I realized very early on, on the very first meeting that we had, that we all had very strong individual personalities. So it made decision-making a lot of back and forth, especially when it came to ideas and stuff. But on that front, the positive side of that is that we didn't have many communication barriers. Everyone spoke their mind, which is good, because then everyone had their equal share in the idea forming. Although, with that came a lot of conflict, and emotions ran high." (Design Course 3-Recycling art student, female, team 12)

Learning from each other and discipline integration:

"I think it comes down to a lot of the respect we have for each individual in the group, and understanding that we are all valuable. And I don't think that has been questioned. I think our actions speak louder than what we can say, and what we've been through and working together." (Design Course 3-Recycling art student, female, team 12)

"I have developed the ability to adapt from them.... I feel like in this course, they walked more into the engineering side, but they're willing to come in and just participate like that. ... They're willing to come in and totally integrate themselves with us, and it's kinda cool to see." (Design Course 3-Recycling engineering student, male, team 14)

"Yeah, they're talking about equilibrium and statics with the sculpture, and they were talking about mechanical components. They were really into the conversation when we were talking about technical 
designs and stuff." (Design Course 3-Recycling engineering student, male, team 12)

"We figured out and also learned how to put different attributes of arts and engineering together to create an actual cool technologically advanced project." (Design Course 3-Recycling engineering student, male, team 14)

Breaking down stereotypes:

"Before, I had no respect for art people. [group teasing reaction] Key word, I said HAD. It's a good process, and I appreciate art pieces now and sculptures. There's a lot more behind it than you think. I started to appreciate it." (Design Course 3-Recycling engineering student, male, team 12)

\section{People-centric STEAM projects:}

The way we structured our STEAM challenges left a lot of freedom for students to choose the approach, materials and overall fabrication of the final project. In this way, individual creativity was encouraged, and each team developed its own team personality. In this regard, our STEAM projects were people-centric, not subject-centric. They put our student personalities and individualities at the forefront.

"I think my big learning experience was just getting the experience of working with other people. In my program, it's always me working on my own. So, I learned a lot of skills that are just teaching me how to communicate better and when things get tough how to work through them. So, I think the first month, I was going home and, I stressed out, a lot. So, every day I was going home like, 'how am I going to do this all summer?"' (Summer internship art student, female, surface tension team)

"Trusting myself was another big thing.... Because going into it, we kinda knew the technological aspects, but there were certain things that we were not sure that we could do - that kinda stressed us out. I'd just say, we are smart, we can do it, just trust yourself." (Summer internship engineering student, male, surface tension team)

Challenge traditional engineering application:
"Understanding the value of collaborating with different people and how much you can push yourself and how much your work can change and you can really compliment each other with integrating both works... Something I can consider doing with my own work is collaborating with other professions." (Design Course 3Recycling art student, female, team 14)

Teaching challenges and discoveries:

"I think it was really unique, but they need to kinda give it a more structure. Yeah, it needs to be more organized." (Design Course 3-Recycling engineering student, male, team 14)

"They're definitely more rigid with their planning that's definitely something new. It's not bad per say. It helped with the whole organization. But it does make things a little difficult, I find, with the evolution of projects. Something I've learned in art is that there's no clear form of what your final project is gonna be - it kinda just evolves over time. But in this case, you needed a clear idea of what you were doing during every stage." (Design Course 3-Recycling art student, female, team 12)

"Labs were difficult to follow along, I found. ... Like, of course it's going to be difficult for them because the way the lab TAs did it - they rushed it and gave up on stuff quickly. They didn't answer their questions, and I feel that they weren't very educated on some of their software." (Design Course 3-Recycling engineering student, male, team 12)

"We started right into coding, first lab, and I was like, 'this is not my scene.' I'm with engineers that, like, I don't know if they know what they're doing or not, but I don't wanna infringe on their course because who wants someone who doesn't know anything coming in and saying 'show me everything'? I wouldn't like that. If it was my course, I'd say we should all be at the same sort of level if we were in one class together. And, yeah, we gave it some more chances, and I'm glad we did." (Design Course 3-Recycling art student, male, team 14)

More similar than different:

"I think the one thing is that we're not as different as the stereotypes were thought to be at the beginning of the 
course [laughs]." (Design Course 3-Recycling art student, female, team 14)

Why vs how to:

"For example, we were talking about our need to anchor our piece into the ground so that it's not topheavy and with the motion it doesn't fall over, and he was like, 'Oh, let's just throw some sandbags on the base to weight it down,' and we're like, 'Well, that is logically a good idea, and it makes sense, but aesthetically it would ruin the piece.' So that wasn't an option." (Design Course 3-Recycling art student, female, team 14) 